\title{
LA JUVENTUd y EL DAÑO EN LA ARGENTINA
}

Florencia Juana Saintout ${ }^{*}$

\begin{abstract}
RESUMEN: Desde hace algunos años asistimos a la presencia de un discurso mediático estigmatizador y deshistorizado que asocia a los jóvenes con la muerte, al construirlos desde múltiples relatos como sujetos peligrosos que ponen la vida propia y ajena en riesgo. Con la pretensión de aportar una mirada que supere la óptica periodística, el presente análisis aborda las prácticas juveniles de riesgo a partir de dos hipótesis: la primera, que las prácticas juveniles donde la vida se pone en riesgo lejos de ser irracionales pueden ser comprendidas en el marco de unos jóvenes socializados en un tiempo de incertidumbre mundial y de vulnerabilidad regional. La segunda conjetura tiene que ver con la relación entre las prácticas juveniles de riesgo y lo que se llamará el daño: las heridas producidas por la dictadura y por 30 años de políticas neoliberales en la región.
\end{abstract}

Palabras Clave: Juventud, enunciaciones mediáticas, representaciones de la muerte, incertidumbre, vulnerabilidad.

\section{INTRODUCCIÓN}

Hubo un tiempo donde la juventud estuvo ligada a la muerte. Como lo señalan Levi y Schmitt (1995), la juventud del medioevo, por ejemplo, fue una "juventud para la muerte". Eran los jóvenes los que iban al frente de la batalla, para proteger a los señores. La muerte como culminación de una vida joven no era algo difícil de aceptar, incluso de anhelar. Fueron siempre jóvenes los que más murieron, los que más mueren en las guerras.

\footnotetext{
* Profesora-investigadora y actual decana de la Facultad de Periodismo y Comunicación Social de la Universidad Nacional de La Plata, Argentina. Correo electrónico: florenciasaintout@yahoo.com.ar
} 
En la década de los setenta en nuestro país la asociación de la juventud con la muerte estuvo condensada en la consigna Patria o Muerte. Los treinta mil desaparecidos fueron mayoritariamente jóvenes.

Pero en la Argentina contemporánea la vida de los jóvenes aparece nuevamente ligada a la muerte. Y no a cualquier muerte, sino a la muerte violenta, aquella que no tiene nada que ver con la calma de la vejez, con los procesos naturales de culminación de la vida (Elias, 1987), ni con 1 a moratoria vital, en tanto supuesta lejanía con respecto a la muerte que caracterizaría lo juvenil (Margulis, 1996). Esta ligazón es construida por los discursos hegemónicos como un dato sin historia, que habla de la irracionalidad de las prácticas y del deterioro de la juventud.

En los últimos años asistimos a la presencia de un discurso mediático que de manera descontextualizada y simplificadora asocia a los jóvenes con la muerte (y desde hace tiempo sabemos que aquello que se dice en los medios, no es sólo cuestión de medios). Desde la perspectiva de varios relatos, que los construyen como delincuentes, como peligrosos que necesitan ser castigados o excluidos del espacio común por no valorar la vida, ni la propia ni la ajena. Como sujetos perdidos que, entonces, son capaces de salir a matar y morir; que se suben a una moto, apagan las luces, y se entregan a la búsqueda de la velocidad y la muerte. Como enfermos que consumen todo tipo de drogas, aun las más fuertes, sin medir riesgos. Como integrantes de bandas con rituales que no se entienden pero donde la vida vale muy poco o nada. Como adolescentes carentes de todo que se involucran en las conductas más riesgosas sin límite alguno, ni siquiera el de la propia muerte.

Se habla de ellos como sujetos ahistóricos que un día sorprenden a la sociedad inocente con un juego que se ve sin sentido y sin posibilidad de ser explicado por nadie. Casi como si existiera en estos jóvenes un mal particular que se cierra y termina sobre ellos.

Me interesa entonces en estas páginas poner en discusión dos ejes del trabajo de investigación comenzando hace ya un tiempo. El primero gira en torno a la idea de que estas prácticas donde la vida está y se le pone en riesgo, lejos de ser irracionales o carentes de sentido, como afirman los discursos periodísticos, pueden ser comprendidas en el marco de unos jóvenes socializados en un tiempo de incertidumbre mundial y de vulnerabilidad regional. Los jóvenes hoy tienen una clara 
conciencia de la vulnerabilidad de la vida. De una vida en donde no hay derechos ni garantías, donde no hay instituciones que los protejan. Me gustaría decirlo lo más claro posible: los límites entre la vida y la muerte son vistos por los jóvenes, y especialmente por ciertos jóvenes, como límites precarios porque viven en un mundo que se ha denigrado como nunca en la historia moderna, con tremendos indicadores de vulnerabilidad. Y esto no es porque sí, no es porque simplemente sucedió, como parecen decirlo ciertos "opinólogos" y periodistas.

La segunda hipótesis, que completa la anterior, tiene que ver con la relación entre esta conciencia de la vulnerabilidad de la vida (y por lo tanto unas prácticas del riesgo que dan como resultado un número altísimo de muertes violentas) con lo que llamaré el daño: las heridas producidas por la dictadura y por 30 años de políticas neoliberales en la Argentina y en la región, de las que los jóvenes hoy portan marcas aún sin saberlo.

A partir de estos ejes de lectura, se desarrolla aquí una serie de reflexiones en torno a diferentes postales mediáticas que han marcado la relación de los jóvenes y la muerte en nuestro país.

\section{ORIENTACIONES TEÓRICAS Y NOTAS METODOLÓGICAS}

Este análisis se ubica en el marco de los estudios de comunicación y cultura. Es decir, que se trata de un trabajo de investigación realizado desde los estudios culturales en el campo de la comunicación. En tal sentido, el análisis se ubica en los márgenes de diversos saberes disciplinarios, pero anclado en una trayectoria específica: aquella que liga la comunicación con los procesos sociales históricos de construcción de sentido, articulando comunicación, cultura y sociedad. La comunicación tiene que ver así con las diferentes formas de estar juntos, las cuales implican sentidos específicos del mundo, sobre plataformas materiales e históricas determinadas.

Desde esta perspectiva, los medios de comunicación son conceptualizados como actores que junto con otros se disputan la capacidad legítima de nombrar al mundo. No intervienen en esta disputa desde la nada, no inventan la realidad, sino que moldean aquello que ya 
está presente en la cultura y la sociedad, de acuerdo con sus intereses (que son históricos, es decir, situados, y en la actualidad básicamente ligados con la reproducción del capital). Por lo tanto, analizar el discurso de los medios no es hablar sólo de los medios, sino de los movimientos de construcción de las hegemonías y las contrahegemonías en un determinado momento histórico.

Partimos, además, del supuesto de que no existe un único modo de ser joven, que no existe la juventud como un todo homogéneo, sino que es posible hablar de diferentes jóvenes de acuerdo con la marca sociocultural de la categoría etaria. Sin embargo, todos ellos comparten una misma época y, por lo tanto, constituyen una generación. Sin duda una de las marcas contemporáneas es la presencia de discursos mediáticos que, mediante mecanismos de focalización, deshistorización y rehistorización, de descontextualización o recontextualización, estigmatizan un amplio espectro de prácticas y representaciones propias de las juventudes. En este artículo, particularmente describiremos los discursos mediáticos sobre los jóvenes que llevan adelante prácticas que ponen en riesgo la vida.

Con este propósito, durante la investigación se monitorearon y analizaron las noticias sobre jóvenes durante el año 2008 para indagar cómo es que los medios representan a los jóvenes y sus concepciones sobre el riesgo y la muerte. La muestra se realizó en 60 horas de videos grabados durante el año 2008. En este proceso se privilegiaron aquellos discursos e imágenes donde los jóvenes son protagonistas de enunciados que describen los ejes que guían la investigación.

La captura del material fue realizada sobre cuatro formatos diferentes: telenovela, noticiero, reality e informe/documental. La decisión de trabajar con formatos audiovisuales tan distintos tuvo como objeto indagar en la posibilidad de encontrar diferencias o puntos en común en gramáticas de producción de mensajes mediáticos heterogéneos. Los programas seleccionados fueron: 1) Noticieros: Telenoche (Canal 13) y Telefé Noticias (Telefé); 2) Reality: Policías en acción (Canal 13); 3) Telenovela juvenil/ficción: Casi Ángeles (Telefé); 4) Informe/documental: La Liga: Mejor hablar de ciertas cosas (América TV).

La indagación, cuya metodología es el análisis cualitativo del contenido de los discursos mediáticos, pretende mostrar las enunciaciones en 
diferentes formatos, así como los horizontes de expectativas desde las que se construyen imaginarios colectivos posibles de ser rastreados en los medios.

\section{EL DAÑo}

En Chile escuché por primera vez la idea del daño. Del daño, de la herida, de aquellas consecuencias de los hechos traumáticos, no siempre accesibles a primera vista, como las de la dictadura, en un modelo de nación que algunos definen como exitoso (fundamentalmente en lo económico) y otros denuncian como excluyente. El daño, como aquello que habla de una dimensión social, histórica, colectiva, pero también profundamente subjetiva, emocional, que se carga en el cuerpo. Un daño, finalmente, que se transmite en diferentes formas de generación en generación.

Asistí en esos días a un congreso donde una investigadora chilena hablaba de la idea del daño para describir la angustia e impotencia enorme que sienten aquellos jóvenes, no todos, de distintos sectores sociales, cuando las vías tradicionales de acceso a la adultez se les han cerrado, y en las nuevas propuestas, básicamente ligadas al consumo, no encuentran un lugar propio. Pensé, mientras escuchaba, en lo sugerente de la noción de daño: estructura y sujeto; sujeto y estructura. Hablar de daño implica hablar de herida, de dolor (carnal, visceral, físico, emocional, sentimental) que se vive en un cuerpo y en un individuo. Y cuando hablamos de daño social, incorporamos la historia a ese cuerpo que se hace también cuerpo colectivo.

Pensé entonces en los jóvenes nuestros (nuestros: de nuestra región; en nuestros alumnos, en los hijos, en los que habitan las esquinas, en nuestras ciudades inmensas); en el daño de las heridas físicas, y también emocionales en los sujetos, y también en la historia. Pensé: ¿En qué consiste el daño de los jóvenes con daño? ¿Quiénes y cómo se hizo el daño? ¿Cómo es vivir dañados? ¿Qué relación existe entre el daño y las formas aparentemente irracionales en las cuales los jóvenes se encuentran cotidianamente con la muerte? ¿Qué hacer con el daño, si es que finalmente se puede hacer algo con ello? 
Estas son preguntas que indican largos caminos, y que seguramente me seguirán acompañando por muchos años, a mí y a otros que desde diversos lugares las transitan. Tal vez en este texto pueda retomar viejos trazos en las cuales, sin hablar directamente del daño, he tratado de explorar las heridas que hoy padecen los jóvenes, simplemente para pensar e hilvanar sobre esta relación entre juventud y muerte que, con certeza, no es una relación que se pueda entender desde el sin sentido o desde la culpabilización que hacen los medios de los jóvenes.

\section{Puntos DE PARTidA}

En primer lugar, es claro que el punto de partida es admitir la herida. Una herida que se hace evidente en los millones de excluidos en la Argentina de comienzos de siglo, como producto de políticas que se instauraron con la dictadura militar y que tuvieron su punto de inflexión en la llamada crisis del 2001, cuando el modelo político, económico y social estalló en mil pedazos, aunque esto no haya implicado su desaparición.

No voy a decir mucho más de esto. Cientos de análisis tocan el tema desde cientos de enfoques. Lo que me interesa es remarcar que aquí se hacen las heridas de las que habla el daño en nuestros jóvenes: ellos no logran salir indemnes. No están afuera. Y no me refiero sólo a los jóvenes como los de la generación del setenta (acallados, perseguidos, exiliados, torturados, desaparecidos), ni tampoco sólo a los del ochenta, los llamados jóvenes de la transición (como si luego del horror fuera posible transitar por la historia hacia algún lugar), sino que estoy hablando también y particularmente de los que hoy son jóvenes. En muchos de los trabajos anclados en las perspectivas de la memoria, cuando se habla de jóvenes hay un detenimiento evidente en los años setenta, en el plano de las militancias políticas; esto es más claro al rescatar el valor de una juventud transformadora, revolucionaria. Pero son pocas las miradas que, desde la necesidad de una memoria activa, se detienen en los jóvenes de comienzos de siglo, cuya existencia está profundamente marcada por la de las generaciones anteriores, por la relación tan fuerte con la muerte. 
La atención de este artículo está puesta, entonces, en esos jóvenes, en un tiempo que a veces, desde las tecnologías de la comunicación, parece de puro presente. Nietos algunos de ellos de la generación que enfrentó la dictadura; hijos otros de los que fueron a Malvinas o de aquellos a los que se llamó los jóvenes de la democracia (los que surgieron a la vida pública con el Juicio a las Juntas, y que rápidamente se encontraron con el Punto final para terminar con el indulto). Voy a detenerme en los jóvenes argentinos que comenzaron a socializarse con el fin del menemismo, o con la crisis del 2001, o con lo que quedó después del estallido. Aquellos que quedaron al frente de lo nuevo, en el frente (de batalla, de enfrentamiento, que primero sufren los avatares) del mundo por venir.

Voy a detenerme en los que están en las escuelas y que, según los maestros, se resisten a ser educados; en los que están limpiando vidrios en las calles y se convencieron de que hay una justicia para unos y otra para ellos; en las chicas que disfrutan el sexo porque ya sus abuelas pelearon por el derecho al goce; en los que levantan la bandera del no político a la política; en los que trabajan en negro y no saben que alguna vez existieron derechos laborales; en las chicas que creen que la maternidad no es un destino y en las que abandonaron la escuela y se embarazan sintiendo que la maternidad es el único camino; en los que creen que no cuidarse del sida es enfrentar un poder que los niega. En todos los que, en esta etapa, son jóvenes, pero lo son con la historia de los padres, de los abuelos, de los bisabuelos en un país y en una región que no sabe muy bien qué hacer con el pasado y que recién está comenzando a imaginar el futuro.

No es posible pensar que lo que los historiadores de la memoria llaman el pasado traumático reciente los haya esquivado. Que no los haya lastimado. Que se hayan "salvado": la dictadura los dañó. Los dañó el neoliberalismo. Los dañó la exclusión. Los daña todos los días. Y en estas heridas tal vez sea posible rastrear algunas de las claves de su cercanía con la muerte, muchas veces como un juego, como un riesgo más, como una forma de anclar los sentidos de la vida. 


\section{LAS HERIDAS}

Empecé hace ya varios años a indagar los modos en que jóvenes ubicados en diferentes lugares del espacio social construyen sus entradas al mundo adulto. Me interesaba ver cómo lo que para las generaciones de sus abuelos había sido un pasaje prefijado y claro, estaba cambiando en un contexto de crisis de las instituciones modernas.

La hipótesis que me guió en el trabajo de investigación estuvo ligada a la idea de que las prácticas y las representaciones de los jóvenes para acceder al mundo adulto y darle sentido no reproducen ahora las estructuras y las instituciones que organizaron la vida durante la modernidad, no "vuelven a ellas sin discusión", sino que en todo caso recrean nuevos principios estructurales. La pregunta central tenía que ver, entonces, con los modos en que distintos jóvenes perciben las instituciones que tradicionalmente cohesionaron la vida social y que hoy están en crisis. Preguntarse por ello era preguntarse a la vez por las formas de imaginar el futuro y por lo tanto, el presente de estos jóvenes. Indagar cómo es que en el marco de la incertidumbre, de la precariedad, los jóvenes están construyendo futuros en relación con sus presentes.

Trabajé con jóvenes diferentes partiendo del supuesto de que no existe un único modo de ser joven, que no existe la juventud como un todo homogéneo, sino que es posible hablar de diferentes jóvenes de acuerdo con la marca sociocultural de la categoría etaria. Sin embargo, todos ellos se exponen a una misma época y, por lo tanto, constituyen una generación.

Cuando cerré la investigación (como se cierran las investigaciones en ciencias sociales: provisoriamente, abriendo otras indagaciones, buscando otras piezas para un rompecabezas construido colectivamente al infinito) una constatación me impactó fuertemente: los evidentes procesos de desciudadanización que atraviesan la constitución de lo juvenil en la actualidad. En el análisis de todas mis conversaciones y entrevistas con jóvenes, en la lectura de una amplia y rica bibliografía producida en los últimos años por investigadores de diversas disciplinas en toda la región, se hace visible un proceso: grandes sectores de la población juvenil en la actualidad desconocen sus derechos y garantías, y menos 
la posibilidad de pelear por ellos: ¿Ante quién hacerlo? ¿Con quién? ¿Qué pelear?, se transforman en interrogantes que no sólo no son capaces de resolver sino que en ocasiones ni siquiera pueden formular. Amplias mayorías de jóvenes se sienten a la deriva, sin ninguna dimensión institucional que los proteja: tienen un saber concreto de la vulnerabilidad y la precariedad.

La desciudadanización es absolutamente clara en el saber de los jóvenes sobre la inexistencia de la condición de desigualdad de cada uno de ellos. Saben, perciben, e incluso casi se podría decir que aceptan (si a este verbo no se le otorgan siempre características de reflexividad consciente o voluntaria) que no todos son iguales, que no poseen los mismos derechos, lo cual se enmarca en la gran dificultad que tiene la mayoría para reconocer que el pasado pudo ser de otra manera. Hay en ellos un claro saber de las restricciones o los límites estructurales que hace que estas generaciones no tengan nada que ver con la opción de imaginar lo imposible.

Finalmente, ligado a lo anterior, me interesa señalar la aceptación por parte de los jóvenes de que no hay marcos regulatorios comunes que indiquen caminos a seguir. No hay una verdad al final, una autoridad común que pueda guiar a nadie, sino que en todo caso deben construir las claves de este nuevo mundo en soledad.

Entonces, con una vida que se juega entre la vulnerabilidad y la ausencia de marcos regulatorios de integración, en un contexto de enormes riesgos donde nada es calmo y predecible: ¿Por qué la muerte tendría que estar domesticada? ¿Por qué tendría que haber una sola muerte, una muerte que integre? ¿Por qué la muerte podría ser regulada? Si la vida es tan veloz, tan precaria, tan hecha de fragmentos y de soledades, ¿qué hay de extraño en que así sea la muerte?

\section{Postales de LA MUERTE}

Cromagnon: A finales del año 2004 nos enteramos en los medios de uno de los hechos más horrorosos de los últimos tiempos: 197 jóvenes muertos en un incendio durante un recital de rock barrial en unas instalaciones absolutamente precarias, fuera de todas las regulaciones 
públicas de seguridad. Los muertos provenían mayoritariamente de sectores populares, y medios, medios bajos. Habían ido a escuchar a una de las bandas del llamado rock chabón, un rock en gran parte inventado por una escucha popular de los cordones del gran Buenos Aires y que toma como paisaje el de la "pobreza, la desocupación, la delincuencia, el tráfico de drogas; en fin, las novedades de la década del noventa" (Semán, 2006: 206). Un rock ciertamente condenado por los rockeros de las décadas anteriores (fundamentalmente integrado por sectores medios urbanos) por considerarlo apolítico: si estos habían hecho música contra el sistema, el nuevo rock barrial pedía la entrada al sistema, con nostalgia de un mundo en que existía la idea del trabajador.

Había en Cromagnon mucha más gente de la que reglamentariamente podía estar: a nadie le importó hacer cumplir las normativas de seguridad. No había puertas de salida, o estaban cerradas. Nada cumplía con las reglamentaciones urbanas. El incendio comenzó cuando se prendió una bengala (práctica extendida en estos recitales) que impactó sobre un techo de poliuretano, material fuertemente inflamable (nadie pudo ver esa relación, la de las bengalas y el poliuretano, evidente y predecible).

En Cromagnon todas las víctimas fueron jóvenes. El horror mostraba otra vez heridas no curadas: la dimensión absolutamente trágica del daño. ¿Qué fue lo que pasó, lo que dio lugar a la masacre? ¿Fue un accidente, una tragedia, una fatalidad? ¿Hay responsabilidad política en los funcionarios en turno del Estado? ¿Hay responsabilidad criminal?

Estas fueron preguntas que durante los meses, los años que siguieron y hasta la actualidad no han podido ser respondidas desde caminos consensuados por la sociedad, sino que por el contrario significaron y significan profundos enfrentamientos. Pero hay dos elementos sobre los cuales nadie tiene duda: la juventud y la vulnerabilidad. Es poco lo que podremos entender de lo que sucedió si no asumimos que las condiciones de precariedad (de instituciones, de normas, de controles) que fueron construidas a lo largo de décadas en la Argentina, de la mano de Estados dictatoriales y Estados Privatizadores, esa noche sostuvieron el horror sobre aquellos que tienen uno de los lugares más vulnerables: los jóvenes. 
Las enunciaciones mediáticas, por su parte, apuntaron en su mayoría a destacar el sinsentido y "la irracionalidad de los que lanzaron bengalas en un local cerrado como un divertimento". Desconocían, de esta manera, las dinámicas sociales y culturales que permiten entender y dar sentido, en estos grupos juveniles, a las prácticas de riesgo en las que se involucran.

Picadas: En muchas de las ciudades del país, el relato es común: por las noches, en calles poco transitadas, más o menos lejanas de los centros, jóvenes de distintos sectores se juntan para hacer picadas, para apostar cuán veloz se puede ser, para correr. Para jugar: el juego "del gallina", de la "ruleta rusa".

El 16 de febrero de 2008 las noticias hablaron de tres jóvenes que junto con otros que los acompañaban cerraron los ojos, se subieron a las motos recién compradas, se "plancharon" y en una ruta de noche corrieron hasta encontrar la muerte: Alejandro Valbuzzi, de 22 años; César Tolosa, de 19; Renzo Blanco, de 18.

El intendente de la ciudad declaró: "Se van a aumentar las multas en lo que hace al tránsito, lo que va a venir bien para corregir la situación". Los amigos hicieron un santuario con cruces y "elementos tuercas", porque los chicos habían muerto "haciendo lo que les gustaba". Los medios nacionales subrayaron al infinito la irracionalidad del juego.

En una entrevista realizada por el equipo de investigación, se le preguntó a uno de los amigos por la velocidad: "El miedo — dijo— en ese momento, se te mezcla con lo que va a venir: vos lo tenés que enfrentar". Hacerse adulto es enfrentar los miedos. "Y cuando manejás, tenés el control". Es imposible no relacionar estas prácticas con la ausencia de trayectorias claras, prefijables y sobre todo colectivas de entrada al mundo adulto. En un momento de ruptura los jóvenes tienen que construir sus propios modos de "hacerse grandes", sin guías, sin marcos de referencia comunes con los adultos. ¿Los padres sabían?, les preguntamos. "A veces sí, a veces no. A veces no quieren saber. Pero de última no importa, porque si lo querés hacer lo hacés."

No hay guías ni referencias que valgan (porque fracasaron, o porque fueron derrotadas, o porque estaban equivocadas, o todo a la vez) y entonces lo tienen que hacer solos. A lo que se suma, además, que en 
sociedades claramente "adultocráticas" como éstas no hay demasiado lugar para los jóvenes, más allá del de ser consumidores; y entonces tener el control de alguna situación, aunque sea la de la propia muerte, no es poca cosa.

Los otros HIJOS: Son varias las investigaciones que tanto desde las ciencias sociales (Míguez, 2008; Kessler, 2004) como desde organizaciones de la sociedad civil han dado cuenta de la criminalización de la juventud, fundamentalmente de aquella que está estructuralmente ligada a la pobreza. De cómo el Estado posdictatorial ha ido alternando políticas democráticas con políticas fuertemente represivas hacia los jóvenes, que han sido acompañadas por la llamada opinión pública.

No voy a detenerme mucho más en esto, lo he hecho en otros trabajos. Sólo señalaré un dato: según la Correpi (Coordinadora contra la Represión Policial e Institucional), en el informe del 2006 existen más de 1900 víctimas de la represión policial, de las cuales 64\% son jóvenes de entre 15 a 25 años. La clasificación indica que $45 \%$ de estas muertes se produjo en cárceles y comisarías, y el resto en episodios de gatillo fácil. El organismo no cuenta los casos de enfrentamientos sino sólo los de represión, cuando la víctima está indefensa y no presenta peligro para terceros.

Estos asesinatos se sostienen sobre una opinión pública que reclama mayor represión sobre unos jóvenes pobres, hijos de más de una generación de no ciudadanos, que se conciben como peligrosos por su incapacidad de valorar la vida. A esto se suma la autopercepción de muchos jóvenes como portadores ellos mismos de una identidad deteriorada.

En una crónica periodística publicada el primer domingo de julio de 2008, Cristian Alarcón habla de los jóvenes en el Bajo Flores. De jóvenes vulnerables, para los cuales la muerte forma parte de la vida cotidiana: sin sacramentos, de manera banal y rutinaria. Él habla en la nota de lo que llama los "hijos" de los transas, los hijos de aquellos que empezados los noventa se hicieron cargo del último eslabón del narcotráfico: la venta de droga a los jóvenes adentro de los barrios y las villas. No puedo dejar de pensar en la línea de continuidad de los HIJOS/de desaparecidos con estos otros HIJOS/de los transas. 
Cuenta Alarcón cómo las matanzas entre los mismos jóvenes son moneda corriente, pero que no se da de manera ostentosa, con pesados rituales como se podría imaginar el enfrentamiento entre bandas, sino que se da de manera cotidiana, con fines borrosos. La muerte puede estar en cualquier esquina, puede salirse a buscar cualquier tarde. Los hijos de los transas, cuenta Alarcón que dicen en el barrio, no necesitan robar: salen a hacerlo por la vergüenza de ser lo que son, para pelear contra el estigma. No hay muchos órdenes sagrados en la vida, por qué habría de haberlos en la muerte.

Sin embargo, la preocupación de Alarcón por recoger y narrar las experiencias de vida de esos jóvenes vinculados con circuitos de economías ilegales es rara en el paisaje mediático argentino. Predomina más bien la invisibilización de esas biografías: "un día Juan le dijo a Matías, o Matías le dijo a Juan, es lo mismo, que si se ponían a vender paco podían acceder a eso, a ser alguien".

\section{LA RESPONSABILIDAD ANTE EL DAÑO}

Sabemos que la muerte, además de ser un hecho biológico ineludible, es un acontecimiento históricamente construido y culturalmente compartido. La muerte no se nos presenta a todos por igual de acuerdo con la época (Ariès, 2007; Lomnitz, 2006; Barley, 2000) y de acuerdo también con el lugar que se ocupe en el espacio social.

Norbert Elias (1987), en La soledad de los moribundos, trabaja la idea de que en las sociedades modernas, de la mano de la extensión de la vida por los procesos de desarrollo científico y las prácticas de la higiene y del cuidado, la muerte puede ser aquello que se sabe pero que es posible, al mismo tiempo, ser "olvidada", puesta entre paréntesis. Pero además, dirá Elias, de acuerdo con los procesos de pacificación social, la muerte podrá ser construida como un acontecimiento natural, de la vejez, en una cama. Para nuestros jóvenes la muerte no es más eso que se espera al final, cuando duelan los huesos de viejo y haya cansancio de la vida. La muerte es en cambio lo que ya no es sagrado, que puede estar a la vuelta de cualquier esquina. 
Los jóvenes no quieren morirse. Ningún joven dice que quiere morirse, lo sabemos muy bien. Pero aunque nadie quiere morir, la muerte está y los jóvenes están nuevamente en el frente. Y no porque sí, como dicen los medios, sino porque algunas de las heridas que se abrieron en la historia todavía no han cerrado. Porque sí hay consecuencias de lo ocurrido y no existe el planeta joven suspendido en el espacio.

Se pregunta Héctor Schmucler (Schmucler, 2007) en un texto desgarrador (y desgarrado):

¿Quiénes son —o somos- los sobrevivientes? ¿Aquellos que estaban en condiciones inmediatas de morir, como los pocos (es pequeñísimo el número si se lo compara con los que murieron) que salieron con vida de los centros clandestinos de detención? ¿Los que eludimos el riesgo de la muerte exiliándonos, es decir, abandonando el campo de una batalla en la que decidimos dejar de participar porque ya no nos interesaba, porque se nos impuso el miedo o porque se nos hizo evidente un error que sólo viviendo podríamos redimir? ¿Los que permaneciendo en la Argentina pudieron sortear el riesgo a que los exponía el haber participado, directa o indirectamente, en las acciones que la dictadura buscaba suprimir? ¿O sobrevivientes somos todos porque estuvimos en peligro, los nacidos y los no nacidos [...] todos los que sin saberlo plenamente llevamos la marca de una época de oprobio de la que yo no puedo despegarme porque las cicatrices me marcan y no quiero disimularlas aunque se hundan en mi propia responsabilidad por lo ocurrido? Estar vivo [...] obliga a hacernos responsables hasta por los muertos.

Yo agregaría: estar vivos nos obliga a hacernos responsables por los vivos también. Es tarea de las ciencias sociales, de la comunicación, tratar de comprender lo que pasa desmontando discursos simplificadores y estigmatizantes. Es tarea de todo el mundo imaginar otro destino para los jóvenes. 


\section{FUENTES CONSULTADAS}

AriĖs, P. (2007), Morir en occidente. Desde la edad media hasta nuestros días, Buenos Aires: Adriana Hidalgo Editora.

Barley, N. (2000), Bailando sobre la tumba. Encuentros con la muerte, Barcelona: Anagrama.

Elias, N. (1987), La soledad de los moribundos, Madrid: Fondo de Cultura Económica.

Glaser, B. y Strauss, A. (1967), The Discovery of Grounded Theory: Estrategies for Qualitative Research, Chicago: Aldine.

Kessler, G. (2004), Sociología del delito amateur, Buenos Aires: Paidós.

Levi, G. y Schmitt, J. (1995), Historia de los Jóvenes, Madrid: Taurus.

Lomnitz, C. (2006), Idea de la muerte en México, México: Fondo de Cultura Económica.

Margulis, M. (1996), La juventud es más que una palabra. Ensayo sobre cultura y juventud, Buenos Aires: Biblos.

Míguez, D. (comp.) (2008), Violencias y conflictos en las escuelas, Buenos Aires: Paidós.

Reguillo, R. (2001), Emergencia de culturas juveniles. Estrategias del desencanto, Buenos Aires: Norma.

Saintout, F. (2006), Jóvenes: el futuro llegó hace rato, La Plata: Ediciones de Periodismo y Comunicación.

SemÁn, P. (2006), "El pentecostalismo y el 〈rock chavón〉 en la transformación de la cultura popular", en Míguez, D. y Semán, P. (coords.), Entre santos, cumbias y piquetes. Las culturas populares en la Argentina reciente, Buenos Aires: Editorial Biblos.

Schmucler, H. (2007), "Carta enviada a La Intemperie", en AA.VV.: No Matar. Sobre la responsabilidad, Córdoba: La Intemperie, Ediciones del Cíclope y Universidad Nacional de Córdoba.

Fecha de recepción: 03 de febrero de 2011 Fecha de aceptación: 14 de octubre de 2013 